\title{
Research of the preliminary deformation and irradiation effect on the viscous damping of dislocations in LiF crystals
}

\author{
G.A.Petchenko \\ O.Beketov National University of Urban Economy, 12 Revolutsii St., \\ 61002 Kharkiv, Ukraine
}

Received March 13, 2013

\begin{abstract}
Pulse-echo method in the frequency range of $37.5-232.5 \mathrm{MHz}$ in LiF crystals at $T=300 \mathrm{~K}$ has been used to study the behaviour of dislocation decrement $\Delta_{d}(f)$ at variations of the residual strain value and X-ray radiation in the range of 0-400 $R$. It has been found out that with the increasing doses of radiation the effect of amplitude damping of the dislocation resonance can be observed which leads to a marked restoration of initial acoustic characteristics of the crystals. It has been discovered that the effective length of the dislocation segment $L$ decreases monotonically, while the coefficient of the dynamic viscosity $B$ retains its value at increasing the crystals irradiation dose. The experimental results have been discussed in the framework of existing theories.
\end{abstract}

Импульсным эхо-методом в диапазоне частот $37,5-232,5$ МГц на кристаллах LiF при $T=300 \mathrm{~K}$ изучено поведение дислокационного декремента $\Delta_{d}(f)$ в условиях варьирования величины остаточной деформации и ренгеновского облучения в интервале 0-400 P. Установлено, что с ростом дозы облучения наблюдается эффект гашения амплитуды дислокационного резонанса, что приводит к заметному восстановлению исходных акустических характеристик кристаллов. Обнаружено, что эффективная длина дислокационного сегмента $L$ монотонно уменьшается, а коэффициент динамической вязкости $B$ сохраняет свое значение при увеличении дозы облучения кристаллов. Результаты опытов обсуждены в рамках существующих теорий.

Вивчення впливу попередньої деформацї̈ та опромінення на рухливість дислокацій у кристалах LiF. Г.О.Петченко.

Імпульсним ехо-методом в діапазоні частот $37,5-232,5$ МГц на кристалах LiF при $T=300 \mathrm{~K}$ вивчено поведінку дислокаційного декремента $\Delta_{d}(f)$ у умовах варіювання величини залишкової деформації і рентгенівського опромінення в інтервалі 0-400 P. Встановлено, що із зростанням дози опромінення спостерігається ефект гасіння амплітуди дислокаційного резонансу, що призводить до помітного відновлення вихідних акустичних характеристик кристалів. Виявлено, що ефективна довжина дислокаційного сегменту $L$ монотонно зменшується, а коефіцієнт динамічної в'язкості $B$ зберігає своє значення при збільшенні дози опромінення кристалів. Результати дослідів обговорено в рамках існуючих теорій.

\section{Introduction}

Currently LiF crystals are widely used as the element base in various acoustic and optic devices. In particular, in medicine and radiobiology dosimeters of radiation have been de- veloped on their basis [1]. In X-ray spectroscopy the crystals of lithium fluoride are used as monochromator crystals and allowed to study the atomic and electronic structure of solids [2]. LiF crystals are also of interest to electronics, nuclear energy [3] and laser tech- 
nology [4]. Undoubtedly, creation of the above mentioned devices with the required service characteristics is possible only on the basis of the research of the crystals physical properties, which substantially depend on the state of the defect structure of the crystal lattice [4]. In particular, deformation of the crystals, as a result of external loads, can cause loss of functional characteristics of the structural elements [2].

In this regard, an investigation of pinning processes of "mobile" dislocations by radiation defects, leading to partial or full restoration of functional characteristics of the above mentioned devices is very relevant applied problem.

To conduct such experiments on LiF crystals, as model objects $[3,4]$ is very interesting scientifically, due to its potential use for testing the various theories described over barrier motion of dislocations. According to [5], in the high-speed, damping of dislocations becomes of dynamic nature and is limited by the transfer of energy from the dislocation to the various quasiparticle excitations in the crystal (electrons, phonons, excitons, other dislocations, etc.). In particular, these crystals, due to an absence of the electronic subsystem, are convenient to study the contribution to the damping of dislocation of phonons, and, possibly, other types of excitations. LiF crystals are quite convenient in comparison with the other ionic crystals, because they have a high Debye temperature $(\theta=732 \kappa)$ [6], which allows at $T=300 \mathrm{~K}$ quite correctly investigate the effects of dislocation pinning by radiation defects, as relaxation processes (except brief post deformation return) at this low temperature practically do not no proceed.

In [7-11], using the high-frequency internal friction method in the frequency range $7.5-232.5 \mathrm{MHz}$, it has been already partially studied the effect of long-wavelength X-rays on the dislocations mobility in LiF single crystals with different residual deformation. The area of minor preliminary deformations have been mainly investigated $(0.3 \%, 0.4 \%$ and $0.65 \%)$, leading to an appearance of large numbers of "mobile" dislocations in the samples, and once under the deformation $\varepsilon=1.5 \%$, at which the "forest" dislocations in the crystal appear, further restricting the mobility of dislocations of the primary slip planes.

The main results, obtained in these studies, are the following. For any of the investigated crystals, the increase in radiation dose has always led to a monotonic shift of the dislocation resonance to higher frequencies and smaller amplitudes. These resonance displacements are accompanied by the decrease in the average effective length of the dislocation loop $L$, which is qualitatively explained by the pinning dislocation of the pinning centers by radiation. In addition, it has been also found that the absolute value of the damping coefficient does not depend on the irradiation time in the range of used doses of 0-400 R.

However, for construction of generalized experimental curves, there is not enough previously collected data. They should be supplemented by new experiment results on LiF crystals with a residual deformation of $1 \%$, which is an intermediate in the range of $0.3-1.5 \%$ strain, which is the purpose of this work.

\section{Experimental}

In this paper, a pulse-echo method in the frequency range of $37.5-232.5 \mathrm{MHz}$ at $T=300 \mathrm{~K}$, the frequency dependence of the dislocation decrement $\Delta_{d}(f)$ in LiF crystals, irradiated with low doses of X-rays in the range of $0-400 R$ has been studied. For the experiments, the samples with a size of $17 \times 17 \times 30 \mathrm{~mm}^{3}$ and purity of $10^{-4}$ wt. $\%$, obtained through puncturing along the cleavage planes $<100>$. After puncturing, the samples were ground and polished so, that non-paralellism of their working surfaces was within $\pm 1 \mu \mathrm{m} / \mathrm{cm}$. The samples were annealed for about $12 \mathrm{~h}$ in a muffle furnace MP-2UM at $\sim 0.8 T_{m}\left(T_{m}=870^{\circ} \mathrm{C}\right)$, followed by slow cooling to room temperature. To put into the crystal "moving" dislocation, it has been preliminary deformed to obtain a residual strain $\varepsilon=1 \%$. Deformation has been performed on compressiontype tensile testing machine "Instron" at a deformation rate of $\sim 10^{-5} \mathrm{~s}^{-1}$. In this mode of deformation, slip bands do not occur, and etching pits uniformly coat the etched crystal surface. This makes possible to count the number of etch pits accurately and determine the density of dislocations $\Lambda$. Irradiation of LiF crystals with X-rays has been performed on a standard installation URS$55(40 \mathrm{kV}, 10 \mathrm{~mA})$. The dose rate at the location of the crystal, determined by dosimeter KID-2, was $\sim 0.11 \mathrm{R} / \mathrm{s}$. The total exposure time was $60 \mathrm{~min}$, and the total dose of irradiation was about $400 \mathrm{R}$. 


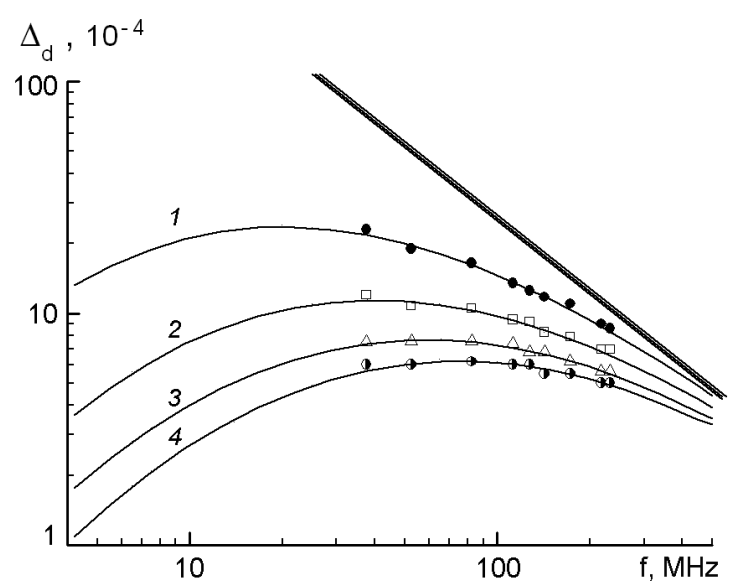

Fig. 1. Frequency dependences of the dislocation decrement for LiF crystals with the value of residual deformation $\varepsilon=1 \%$ at room temperature with the different irradiation time: 1,2,3,4 - theoretical curves [12], straight lines - their high-frequency asymptotes for the samples with irradiation time $0,20,40$ and $60 \mathrm{~min}$, respectively.

\section{Results and their discussion}

Fig. 1 shows the research results of the frequency dependence of dislocation decrement $\Delta_{d}(f)$ for LiF samples with a residual deformation $\varepsilon=1 \%$, measured before irradiation (curve 1) and after it (curves 2-4). It can be noted, that with an increase of the irradiation time, resonance curves $\Delta_{d}(f)$, decreasing in the height, monotonically shifted toward the higher frequencies. The experimental points are well described by the theoretical frequency profile [12], calculated for the case of exponential distribution of the dislocation loops in length. It also shows, that high-frequency asymptote for these theoretical profiles $1-4$ are almost identical. It should be particularly noted the fact that the most noticeable curve shift $\Delta_{d}(f)$ occurs at the initial irradiation stage, during 20-40 min (curve 2-3). Later on, with the increasing radiation dose, a displacement of the dislocation resonance becomes less pronounced. It should be mentioned, that the binding of the theoretical curves [12] to the experimental data has been carried out with a focus on the points that lie on the descending branch of the experimental curve and in the resonance area.

Fig. 2 demonstrates the shift effect with irradiation of the resonance peak parameters in amplitude and frequency. The course of time dependences $\Delta_{m}(t)$ and $f_{m}(t)$ shows, that under conditions of the radiation dose

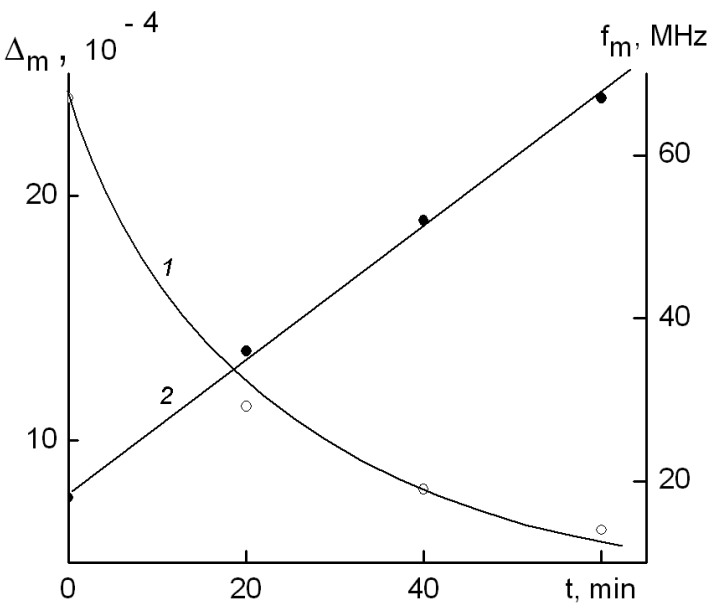

Fig. 2. Dependences of the irradiation time: 1 - dislocation decrement at the maximum $\Delta_{m}$, 2 - resonance frequency $f_{m}$ for LiF crystals.

rise up to 396 roentgen, the magnitude of the dislocation decrement $\Delta_{m}$ in the maximum dramatically reduces, and its resonance frequency $f_{m}$ increases at that time.

To get information on the dependence of the average effective length of the dislocation segment $L$ and the coefficient of dynamic damping of dislocations $B$ on the radiation dose, the data shown in Fig. 1 and 2 were processed in the framework of the theory [12] using the equations described the position of the resonance peak and descending branch of the dependence $\Delta_{d}(f)$ :

$$
\begin{gathered}
\Delta_{m}=2.2 \Omega \Delta_{0} \Lambda L^{2} ; f_{m}=\frac{0.084 \pi C}{2 B L^{2}} ; \\
L=\sqrt{\frac{0.084 G b^{2}}{B f_{m}(1-v)}}
\end{gathered}
$$

where $\Omega-$ an orientation factor, that takes into account, that the given shift stress in the slip plane is less than the applied voltage; $\Delta_{0}=\left(8 G b^{2}\right) /\left(\pi^{3} C\right), C=2 \cdot G b^{2} / \pi(1-v)-$ an effective tension of the curved dislocation; $\Lambda$ - a dislocation density; $v-$ the Poisson's ratio; $G$ - a shift modulus of the current slip system, $b$ - the Burgers vector. Borrowing the calculated in [13] values of $\quad \Omega=0.311 ; \quad C=2.5 \cdot 10^{9} \quad \mathrm{~N} ; \quad \Lambda=$ $2.5 \cdot 10^{10} \mathrm{~m}^{-2} ; v=0.27 ; G=3.533 \cdot 10^{10} \mathrm{~Pa} ; b=$ $2.85 \cdot 10^{-10} \mathrm{~m}$ and $G b^{2}=28.7 \cdot 10^{-10} \mathrm{~Pa} \cdot \mathrm{m}^{2}$, in the present work, grounding on the above mentioned formulas, the dependence of the parameters $L$ and $B$ from the time of X-ray irradiation has been defined. It has been established, that the value of $B$ retains its 


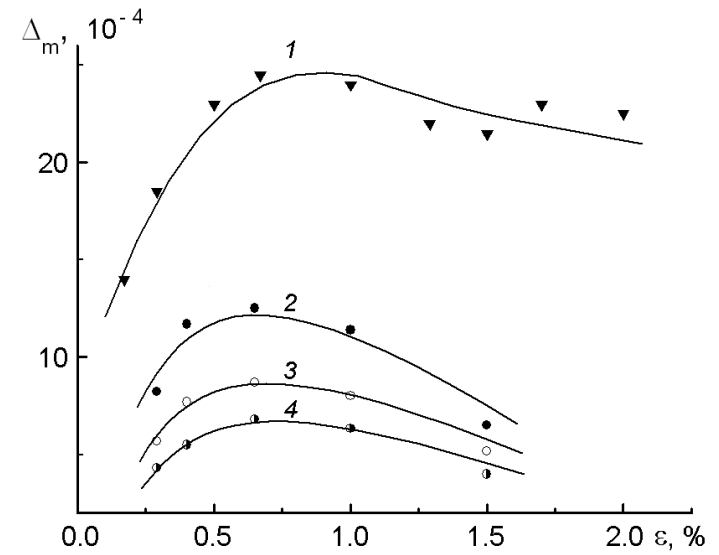

Fig. 3. Dependences of the dislocation decrement at the maximum $\Delta_{m}$ from the value of residual deformation $\varepsilon$; curve 1 - unirradiated crystal, curves $2-4$ for the crystals with irradiation time $0,20,40$ and $60 \mathrm{~min}$, respectively.

absolute value, and the segment length $L-$ monotonically decreases with the rise of the radiation dose in the range of $0-400 \mathrm{R}$.

Using the data of the present work and the results obtained earlier in the [7-11], dependence of the parameters of the resonance peak on the deformation $\Delta_{m}(\varepsilon)$ and $f_{m}(\varepsilon)$, shown in Fig. 3 and 4 , have been formulated.

Fig. 3 (curve 1) shows that the dependence $\Delta_{m}(\varepsilon)$ for the non-irradiated crystal is altered in non-monotonic way. With the deformation increase the increase in dislocation decrement is firstly observed, and then, after passing its peak, the value of $\Delta_{m}$ starts to decrease. With the onset of the crystal irradiation the localization of the experimental curves $\Delta_{m}(\varepsilon)$ is changing. Now, with a higher dose of radiation, they begin to decline significantly in height. The most significant decrease is seen during obtaining the first dose of irradiation by crystals (Fig. 3, curve 2), and then the rate of this decrease in amplitude is gradually slowing down (curves 3, 4). It should be noted, that although the curves $\Delta_{m}(\varepsilon)$ shift in amplitude, their non-monotonic mode at different doses of irradiation retains.

The usage of the above mentioned data set makes it possible to trace the performance of the group of the experimental curves $f_{m}(\varepsilon)$.

As it has been expected, the non-monotonic nature of the shift with the deformation is shown not only for $\Delta_{m}(\varepsilon)$, but also

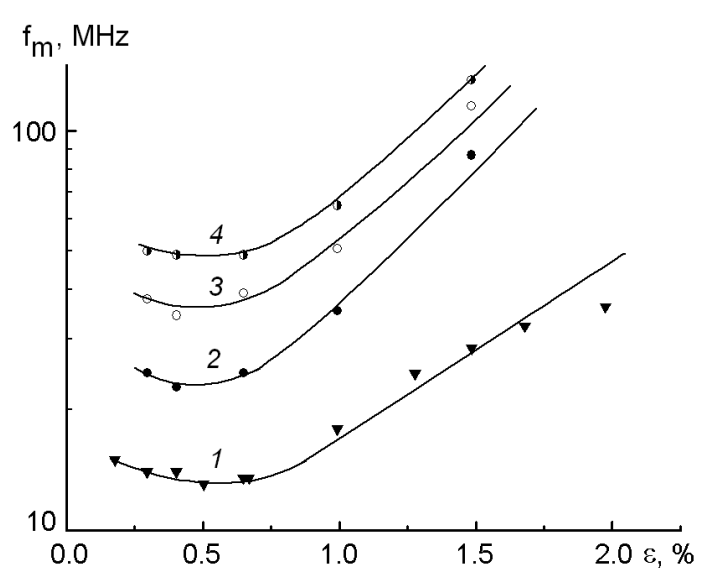

Fig. 4. Dependences of the resonance frequency $f_{m}$ from the value of residual deformation $\varepsilon$; curve 1 - unirradiated crystal, curves $2-4$ for the crystals with irradiation time $0,20,40$ and $60 \mathrm{~min}$, respectively.

for the resonance frequency $f_{m}(\varepsilon)$ (Fig. 4, curve 1). However, it differs - that up to the value of residual strain $\varepsilon \approx 0.65 \%$ resonant frequency $f_{m}$ at first decreases with increasing $\varepsilon$, and then, after passing through a minimum, begins to increase. As for the behavior of radiation dependence $f_{m}(\varepsilon)$, the situation is also different from that, which was characteristic for the curves $\Delta_{m}(\varepsilon)$. At a dose of irradiation of $132 \mathbf{R}(t=20 \mathrm{~min})$ the experimental curve $f_{m}(\varepsilon)$ markedly shift towards higher frequencies. With a further increase in the dose of irradiation (Fig. 4, curves 3,4 ) the growth tendency of $f_{m}$ value is preserved, but the rate of increase is gradually decreasing. It should be noted, that the nonmonotonic shape of the curve $f_{m}(\varepsilon)$ is preserved for the irradiated crystals too.

From the analysis of the generalized data shown in Fig. 3 and 4, it is seen that increasing radiation doses up to $\sim 400 \mathrm{R}$ ( $t=$ $60 \mathrm{~min}$ ) leads to a substantial reduction in the amplitude of the dislocation resonance and its shift towards the higher frequencies. As a result of the dislocation resonance damping effect, caused by the decrease in the dislocations mobility, there is a noticeable recovery of the original acoustic characteristics of the crystals.

Using the resulting data shown in Fig. 3 and 4 , in the present study there have been defined the dependences of parameters $L$ and $B$ according to the dislocation density $\Lambda$ shown in Fig. 5. 
Fig. 5 (curve 1) shows, that an increase in the density of dislocations $\Lambda$ in the crystal, the value of $L$ firstly increases and then, reaching its maximum value starts to decrease monotonically. As in [13], its change, along with changes in the resonance peak parameters, is well explained by the model of dislocation interactions [14]. According to [14], together with the start of the plastic deformation in the crystal, a detachment of the existing "grown-in" dislocation occurs and the new sources appear, that generate the long dislocation loops, which increase leads to an increase in the maximum decrement $\Delta_{m}$ and decrease in the maximum resonance frequency $f_{m}$ with the deformation (Figs. 3 and 4). However, starting from the deformation of about $0.65 \%$, dislocations occur in other slip planes, which have a pinning effect on the dislocations, lying in a primary plane. As a result of this indicated interdislocation interaction, the value of $L$ starts to decrease, which is manifested in the reduction of dislocation loss of ultrasound and the shift of damped dislocation resonance to higher frequencies area. Results for $L(\Lambda)$, obtained for the irradiated crystals (curves 2-4) are not qualitatively different from those obtained for the non-irradiated crystal (curve 1). However, it is clear, that, with increasing the radiation dose, the curves $L(\Lambda)$, more and more reduced in height, which probably indicates an active interaction of the dislocations with radiation-induced dislocation pinning centers.

For the convenience of the transition from the values of the preliminary deformation $\varepsilon$ to the densities of dislocations $\Lambda$ in Fig. 5 (in the form of an insert page), it has been shown the dependence $\Lambda(\varepsilon)$, which we have obtained earlier for LiF in paper [13].

Fig. 5 (curve 5) shows the obtained functional relationship between the parameters $B$ and $\Lambda$ for LiF crystals. Note, that each of the experimental data points, related to the deformation of $0.3 \%, 0.4 \%, 0.65 \%, 1 \%$ and $1.5 \%$ is the average result of all the $B$ values, obtained before and after irradiation in the dose range of $0-400 \mathrm{R}$. It can be seen that the results presented in $B(\Lambda)$ for LiF, do not only correlate well with the similar data obtained on $\mathrm{KBr}$ crystals [15], $\mathrm{KCl}$ [16], and $\mathrm{NaCl}$ [17], indicating the independence of the damping coefficient $B$ from value of $\Lambda$, but also show the independence of the parameter $B$ from the time of irradiation in the dose range of $0-400 \mathrm{R}$. And this means

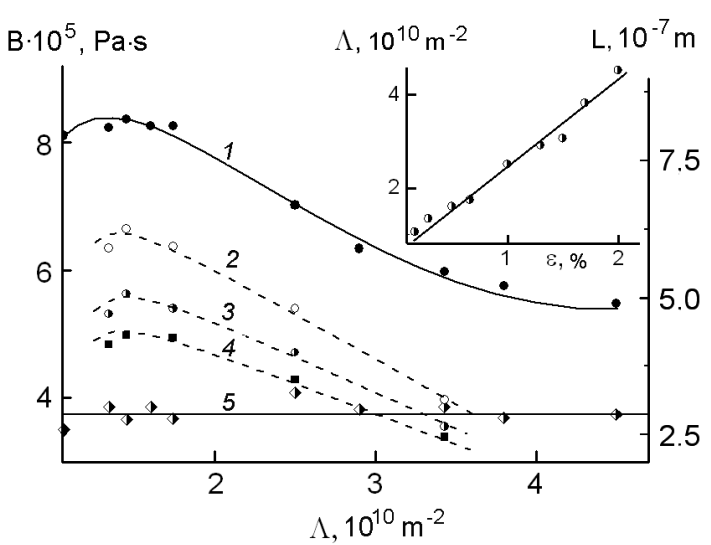

Fig. 5. Dependences of the average effective length of the dislocation segment $L-1-4$ and the coefficient of dynamic damping of $B$ -5 from the dislocation density $\Lambda$. No interrupted line 1 - for the unirradiated crystal, dotted curves 2-4 - for the crystals with irradiation time $0,20,40$ and $60 \mathrm{~min}$ respectively; insert page - dependence $\Lambda(\varepsilon)$, taken from [13].

that the values of $B$ at these experimental conditions are determined only by the interaction of dislocations with the phonon gas, which correlates with the conclusions of the research [18]. As for the other mechanisms, stipulated by the interaction "dislocationdislocation" [19] and "dislocation-impurity (radiation) center", their contribution into the damping, as well as in the electronic component in metals [5], is small, and at room temperature due to masking of the phonon component can not be shown.

\section{Conclusions}

Using pulse-echo method in the frequency range of $37.5-232.5 \mathrm{MHz}$ on $\mathrm{LiF}$ crystals with the magnitude of the residual deformation of $1 \%$ at $T=300 \mathrm{~K}$, the performance of the frequency spectra of the dislocational ultrasonic absorption $\Delta_{d}(f)$ under conditions of changes of X-ray irradiation dose in the range of $0-400 \mathrm{R}$ has been studied. It has been shown, that an increase of the radiation dose causes a change in the frequency and amplitude localization of the curves $\Delta_{d}(f)$. The influence of the preliminary deformation in the range of $\varepsilon=0.3-1.5 \%$ and small doses of X-ray irradiation in the range of $0-400 \mathrm{R}$ on the run of the resonance parameters $\Delta_{m}(\varepsilon)$ and $f_{m}(\varepsilon)$ for LiF crystals has been analyzed. It has been found out that with an increase of the doses up to $\sim 400 \mathrm{R}$, there is a signifi- 
cant suppression of the amplitude of the dislocation resonance which leads to a marked recovery of initial acoustic characteristics of the crystals. The behavior of the average effective length of the dislocation segment $L$ at the changes in the dislocations density in LiF crystals has been studied under conditions of varying the dose of $\mathrm{X}$ rays in the range of $0-400 R$ at $T=300 \mathrm{~K}$. The mode of the obtained dependences $L(\Lambda)$ is explained in the framework of the model of dislocation interactions and the processes of dislocation pinning radiation-induced defects. It has been shown that the coefficient of the dynamic viscosity $B$ remains in its value, as at the variation of dislocation density and at the irradiation time in the dosage range of $0-400 \mathrm{R}$. This means, that the values of $B$ at the stated experiment conditions, are determined only by the phonondislocation interaction. Contribution to the damping of other mechanisms, caused by the interaction of the moving dislocation with other dislocations, impurity and radiation centers, as well as the electronic component in metals, is small, and at room temperature can not be shown due to the masking of the phonon component.

\section{References}

1. F.Daniels, Ch.Boud, D.Saunders, Uspekhi Fiz. Nauk, L1(2), 272 (1953).

2. M.I.Mazuritsky, X-ray Optics, Rostov State University, Rostov on Don (2005) [in Russian].
3. I.M.Neklyudov, A.K.Malik, A.A.Parkhomenko, A.V.Rudnitsky, Probl.Atom.Sci. Techn., 93, 52 (2009).

4. I.A. Parfianovich, E.E. Penzina, Electronic Color Centers in Ionic Crystals, East-Siberia Book Publishing House, Irkutsk (1977) [in Russian].

5. V.I.Alshits, V.L.Indenbom, Uspekhi Fiz. Nauk, 115, 3 (1975).

6. R.Truell, C.Elbaum, B.Chik, Ultrasonic Methods in Solid State Physics, Mir, Moscow (1972) [in Russian].

7. G.A.Petchenko, A.M.Petchenko, Functional Materials, 17, 421 (2010).

8. G.A.Petchenko, Probl.Atom.Sci.Techn., 2, 36 (2012).

9. G.A.Petchenko, Vistn.Khark.Nats.Univers., 1019, 57 (2012).

10. G.A.Petchenko, Ukr.Zh.Fiz., 49, 339 (2011).

11. G.A.Petchenko, Functional Materials, 19, 473 (2012).

12. A.Granato, K.Lucke, J.Appl.Phys., 27, 583 (1956).

13. A.M.Petchenko, G.A.Petchenko, Vistn. Khark. Nats. Univers., 865, 39 (2009).

14. A.Hicata, R.Truell, A.Granato et al., J.Appl. Phys., 27, 396 (1956).

15. G.A.Petchenko, Functional Materials, 4, 785 (2000).

16. O.M.Petchenko, G.O.Petchenko, Ukr.Zh.Fiz., 6, 716 (2010).

17. A.M.Petchenko, V.I.Mosgovoj, A.A.Urusovskaya, Fiz. Tverd. Tela, 10, 2992 (1988).

18. N.P.Kobelev, Ya.M.Soyfer, V.I.Alshits, Fiz. Tverd. Tela, 4, 1172 (1979).

19. V.D.Natzik, E.V.Minenko, Fiz.Tverd.Tela, 12, 2099 (1970). 